\title{
Creating a proof-of-concept climate service to assess future renewable energy mixes in Europe: An overview of the C3S ECEM project
}

\author{
Alberto Troccoli ${ }^{1,2}$, Clare Goodess ${ }^{1}$, Phil Jones ${ }^{1,3}$, Lesley Penny ${ }^{1}$, Steve Dorling ${ }^{1,2}$, Colin Harpham ${ }^{1}$, \\ Laurent Dubus ${ }^{4}$, Sylvie Parey ${ }^{4}$, Sandra Claudel ${ }^{4}$, Duc-Huy Khong ${ }^{4}$, Philip E. Bett ${ }^{5}$, Hazel Thornton ${ }^{5}$, \\ Thierry Ranchin ${ }^{6}$, Lucien Wald ${ }^{6}$, Yves-Marie Saint-Drenan ${ }^{6}$, Matteo De Felice ${ }^{7}$, David Brayshaw ${ }^{8}$, \\ Emma Suckling ${ }^{8}$, Barbara Percy ${ }^{9}$, and Jon Blower ${ }^{8,9}$ \\ ${ }^{1}$ UEA, School of Environmental Sciences, Norwich, UK \\ ${ }^{2}$ World Energy \& Meteorology Council, Norwich, UK \\ ${ }^{3}$ Center of Excellence for Climate Change Research, Department of Meteorology, \\ King Abdulaziz University, Jeddah, Saudi Arabia \\ ${ }^{4}$ EDF R\&D, Paris, France \\ ${ }^{5}$ Met Office Hadley Centre, Exeter, UK \\ ${ }^{6}$ MINES ParisTech, PSL Research University, O.I.E. - Centre for Observation, \\ Impacts, Energy, Antipolis, France \\ ${ }^{7}$ ENEA, Bologna, Italy \\ ${ }^{8}$ University of Reading, Reading, UK \\ ${ }^{9}$ Institute for Environmental Analytics, Reading, UK \\ Correspondence: Alberto Troccoli (alberto.troccoli@wemcouncil.org)
}

Received: 25 February 2018 - Revised: 3 July 2018 - Accepted: 21 July 2018 - Published: 23 August 2018

\begin{abstract}
The EU Copernicus Climate Change Service (C3S) European Climatic Energy Mixes (ECEM) has produced, in close collaboration with prospective users, a proof-of-concept climate service, or Demonstrator, designed to enable the energy industry and policy makers assess how well different energy supply mixes in Europe will meet demand, over different time horizons (from seasonal to long-term decadal planning), focusing on the role climate has on the mixes. The concept of C3S ECEM, its methodology and some results are presented here. The first part focuses on the construction of reference data sets for climate variables based on the ERA-Interim reanalysis. Subsequently, energy variables were created by transforming the bias-adjusted climate variables using a combination of statistical and physically-based models. A comprehensive set of measured energy supply and demand data was also collected, in order to assess the robustness of the conversion to energy variables. Climate and energy data have been produced both for the historical period (1979-2016) and for future projections (from 1981 to 2100, to also include a past reference period, but focusing on the 30 year period 2035-2065). The skill of current seasonal forecast systems for climate and energy variables has also been assessed. The C3S ECEM project was designed to provide ample opportunities for stakeholders to convey their needs and expectations, and assist in the development of a suitable Demonstrator. This is the tool that collects the output produced by C3S ECEM and presents it in a user-friendly and interactive format, and it therefore constitutes the essence of the C3S ECEM proof-of-concept climate service.
\end{abstract}




\section{Introduction}

The electric energy sector is undergoing a major transformation. The established model, of traditional thermal power plants providing most of the "firm" power to match variable levels of demand, is being challenged by the steadily increasing share of power supply from temporally-variable renewable energy sources, such as wind and solar power (e.g. REN21, 2016). Demand variability is also increasing as a result of the widespread use of embedded small-scale generation (e.g., rooftop solar PV) and air conditioning, and can further change in response to price signals. At the same time, the cost of batteries has started to noticeably decrease, making electricity storage increasingly economically viable (Frankel and Wagner, 2017). This transformation in the energy sector is taking place against a variable and changing climate. Given the weather- and climate-dependency of both renewable energy and demand - even in the case of large storage uptake - it is important to develop robust climate-based tools that can assist energy planners, market operators and policy makers (Silva and Burtin, 2015).

Recent projects or studies that have assessed future energy scenarios normally do not fully consider the effect of a variable and changing climate (e-HW2050, 2015; Silva and Burtin, 2015). While this may not be the main driver of future energy planning, it is likely that long term changes in variables like temperature and precipitation will affect the volume of energy that is used and produced on timescales of decades (e.g., Bloomfield et al., 2016; van Vliet et al., 2016; Pfenninger and Staffell, 2018). It is therefore important to assess and quantify the level of changes in climate variables that will drive the future energy systems, both from a climate and energy perspective, while also recognising that different energy outcomes need to be considered. For instance, he e-Highway 2050 project $^{1}$ (e-HW2050) selected five energy scenarios, amongst those developed by the EU roadmap 2050 reference. These five scenarios were chosen to be substantially different from each other, while also challenging the entire existing European electricity system, not just the transmission grid.

In order to assist the energy sector in understanding the role of climate on energy systems, and uptaking this climate information, the EU Copernicus Climate Change Service (C3S), a programme started in 2015, has taken as one of its foci the development of climate services for the energy industry, such as through the European Climatic Energy Mixes (ECEM) project. The C3S ECEM's aim has been to produce a proof-of-concept climate service, or Demonstrator, to enable the energy industry and policy makers to assess

\footnotetext{
${ }^{1}$ e-Highway 2050 was an EU project (2012-2015), participated in by a large number of Transmission System Operators (TSOs), energy companies and research institutions, that investigated a number of scenarios for power production across Europe (http://www. e-highway2050.eu, last access: 3 July 2018).
}

how well different energy supply mixes in Europe could meet demand, over different time horizons (from seasonal to longterm decadal planning), focusing on the role climate has on the mixes. This objective has been tackled through a close interaction with stakeholders, in a framework that allows for co-design of the service.

The C3S ECEM Demonstrator is constituted of a visual tool to display and investigate climate and energy data, along with a comprehensive set of documentation such as factsheets, methods and assumptions, key messages, event case studies and frequently asked questions. It also has the option to enter feedback for the developers of the Demonstrator to take on board. However, response to users' queries, data updates or fixes are not acted upon within set time frames. Thus, while the Demonstrator has been developed following detailed guidelines (as described in the C3S ECEM data management plan) in preparation for the future C3S operational service for the energy sector, it is a (pre-operational) proof-of-concept climate service, rather than a fully-fledged (operational and/or commercial) climate service.

The C3S ECEM project started in November 2015, and represents a collaboration between teams from the University of East Anglia (UEA, UK), Électricité De France (EDF, France), the Met Office (UK), MINES ParisTech/Armines (France), the University of Reading (UK) and the Agency for new technologies, energy and sustainable development (ENEA, Italy). The project has a duration of 29 months.

The specific underlying challenges motivating C3S ECEM are:

- To describe the ways in which energy supply and demand over Europe are affected by the spatial and temporal variations of their climate drivers

- To produce scenarios that demonstrate how different energy supply mixes can meet demand at the European scale, particularly given the projected high level of highly climate-sensitive renewable energies.

To this end, the C3S ECEM has produced consistent and high-quality datasets for climate and energy variables, selected for their relevance for the electric energy sector. These datasets can be explored and downloaded through a flexible and user-friendly platform, provided by the Demonstrator. The datasets and Demonstrator, as well as the underlying energy conversion models, have been developed by subject experts in close collaboration with energy sector users. The Demonstrator allows to explore relationships between climate and energy over the last 40 years and the effects of climate change over coming decades, as well as assessment of the skill of seasonal forecasts. As mentioned, a wide range of documentation and guidance is also provided with the Demonstrator.

This paper provides an overview of the main aspects of the C3S ECEM based on a presentation given at the 2017 


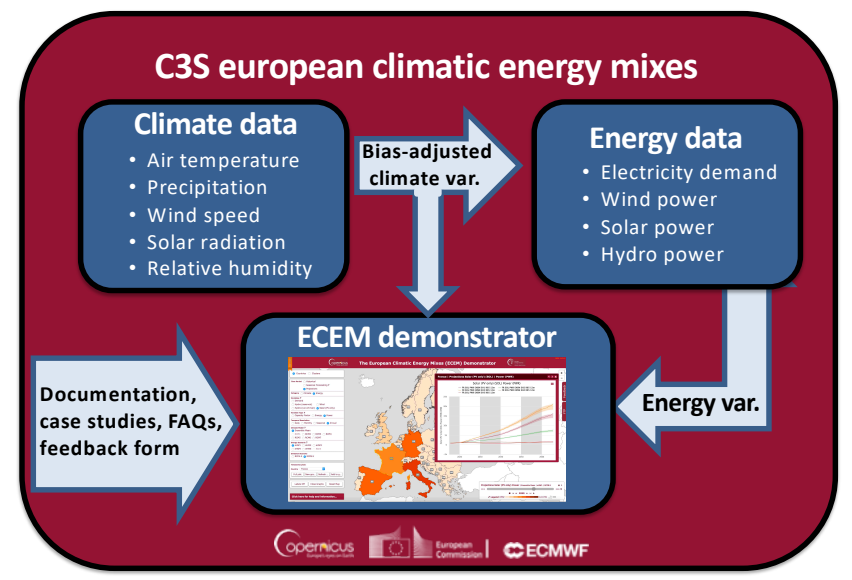

Figure 1. Overview of the C3S ECEM project. Climate data of relevance to the energy sector (top left) are first bias -adjusted and then converted into energy variables through statistical modelling or transfer functions. Climate and energy variables (var.) produced by the C3S ECEM are presented via the Demonstrator (inset figure expanded as Fig. 2) together with a wide range if documentation. For more information, see: http://ecem.climate.copernicus.eu/ demonstrator/ (last access: 3 July 2018).

European Meteorological Society Conference in Dublin (Ireland). The main elements of C3S ECEM are shown in Fig. 1. Section 2 discusses the work on the bias-adjustment of climate variables relevant for the energy sector over the historic period (1979-2016), for projections (out to 2100), and including the assessment of seasonal climate retrospective forecast skill. The conversion of climate variables into energy supply and demand variables is the next step, described in Sect. 3. The conversion is performed using models that offer a good compromise between accuracy and flexibility to model each country in Europe with the available measured data. In Sect. 4 we describe the main aspects of stakeholder engagement in the C3S ECEM project, leading to the development of the C3S ECEM Demonstrator tool described in Sect. 5. The final Sect. 6, offers some concluding remarks as well as an outlook for the next phase of the project, including the pre-operational phase of the Demonstrator.

\section{Bias-adjustment of climate variables relevant for the energy sector}

In the C3S ECEM project, bias-adjustment methods and tools for the development of some of the Essential Climate Variables (ECVs, Bojinski et al., 2014) relevant for the energy sector have been developed for the historical period (1979-2016). These bias-adjusted historical variables provide a reference for the bias-adjustment (or calibration) of seasonal climate predictions and climate projections.

Given the large domain covered by C3S ECEM, reanalyses are preferred to direct observations. The former has the specific advantage of being spatially and temporally complete through the process of physical/dynamic representation of the climate system which provides internally consistent fields across most surface atmospheric variables as well as in the atmospheric column up to the stratosphere (Compo et al., 2011). Aside from being used in reanalyses, observations are here used as reference in our bias-adjustment procedures.

\section{Historical period}

A preliminary assessment of different reanalysis products ERA-Interim (Dee et al., 2011), JRA-55 (Kobayashi et al., 2015) and MERRA (Rienecker et al., 2011) - for surface air temperature, precipitation and solar radiation for the European domain $\left(27^{\circ}-72^{\circ} \mathrm{N}\right.$ by $\left.22^{\circ} \mathrm{W}-45^{\circ} \mathrm{E}\right)$ was conducted as an initial step. Each product was re-gridded to the $0.5^{\circ}$ grid for this domain and compared against observational gridded and station-based products (Haylock et al., 2008; Becker et al., 2013; Harris et al., 2014; Weedon et al., 2014). On average, ERA-Interim performed somewhat better than the other reanalyses over the European domain, so for the purposes of the project it was decided to retain ERA-Interim only.

All reanalysis products are potentially biased when compared with observations, so a major task in C3S ECEM has been to assess possible bias-adjustment approaches available in the scientific literature. A number of different biasadjustment approaches have been proposed. In the methodology we have adopted, the parameters of different distributions (depending on the variable) are modified, adjusting those calculated from ERA-Interim to those based on gridded observations or direct station measurement (details are provided in Jones et al., 2017). Specifically, the following energy-relevant ECVs have been bias-adjusted:

- Air Temperature (TA)

- Precipitation (TP)

- Wind Speed (WS) at 10 and at $100 \mathrm{~m}$

- Solar Irradiance (GHI)

- Relative Humidity (RH)

These are the most important variables for the computation of the energy indicators developed in C3S ECEM, as also established via stakeholder consultations. Two other ECVs, Pressure at Sea Level (PSL) and Snow Depth (SD), have also been considered but these have not been bias-adjusted ${ }^{2}$; their country and cluster ${ }^{3}$ averages are therefore provided based on the original ERA-Interim.

\footnotetext{
${ }^{2}$ In the case of PSL this is considered a well simulated variable and in the case of SD observed datasets are not readily available.

${ }^{3}$ The clusters used in C3S ECEM are taken directly from the e-Highway2050 project. These are aggregates of Nomenclature of Territorial Units for Statistics (NUTS)-3 regions.
} 


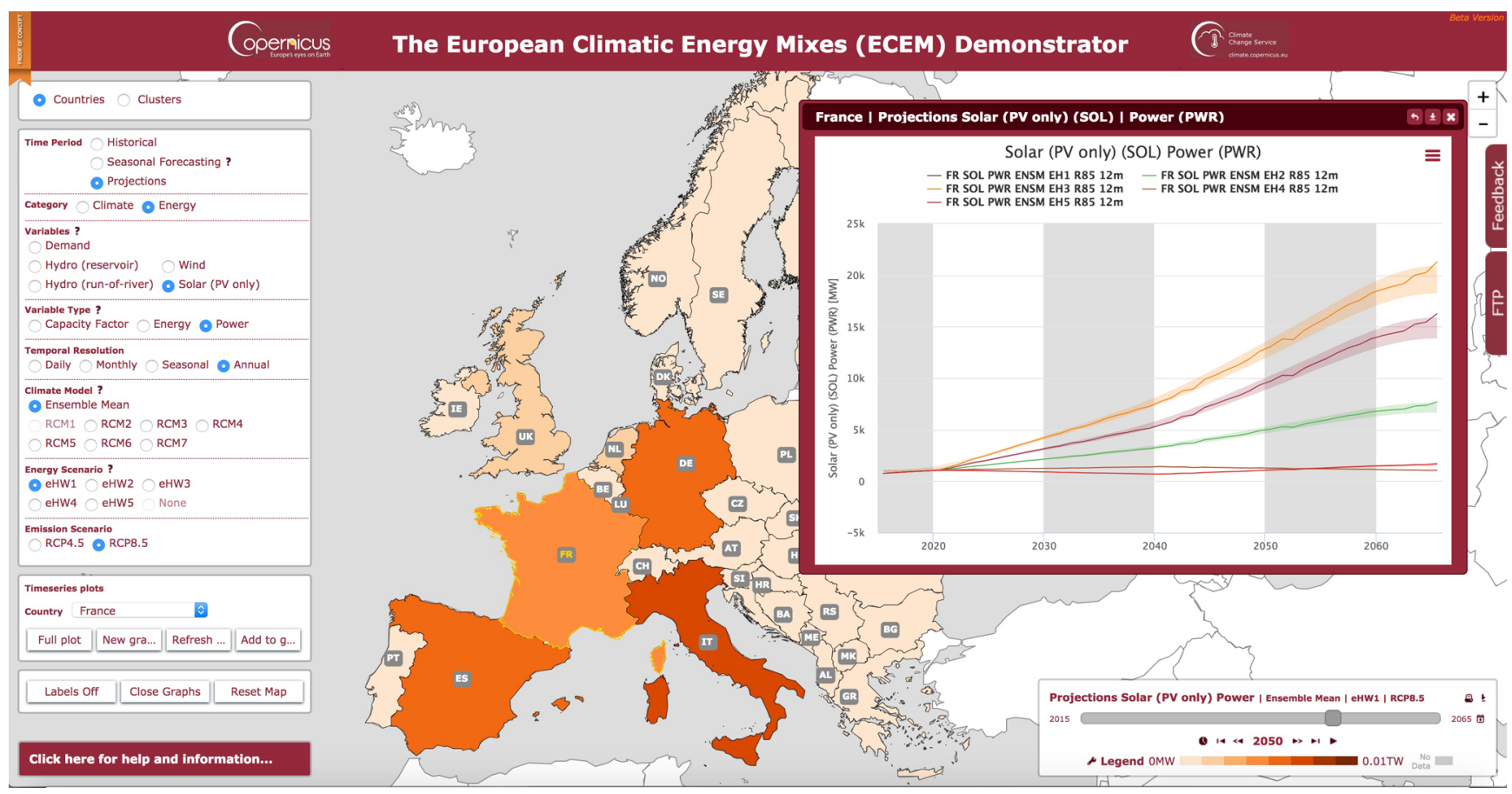

Figure 2. Screenshot of the C3S ECEM Demonstrator. It shows solar power for France for the projection period (RCP8.5) for the five e-Highway2050 scenarios described in the text (time series plot) and for Europe (underlying map) for year 2050 for the first e-Highway2050 scenario (purple line in the timeseries). Comprehensive documentation about the Demonstrator is available at the bottom left hand side of the Demonstrator (http://ecem.climate.copernicus.eu/demonstrator/, last access: 3 July 2018).

Note that wind speed at $100 \mathrm{~m}$ is calculated using a power law relationship from wind speed at $10 \mathrm{~m}$. This relationship is simpler than other methods as it is independent of roughness lengths, namely WS100 $=(100 / 10)^{\alpha}$. WS10, with $\alpha=$ 0.143 , corresponding to neutral condition of the air column. Also, bias adjustment for RH is first applied to the dewpoint depression (air minus dewpoint temperature). Bias adjustment is only performed for land areas. Users wanting offshore series (e.g. for wind) should use the original ERAInterim data ${ }^{4}$.

The benefit of performing bias-adjustment is demonstrated by comparing original and bias-adjusted ERA-Interim data (as monthly averages for the 1979-2014 period) against the same observations. This may seem circular, but our approach adjusts the distributions, not the long-term average. In Jones et al. (2017) the differences between our bias-adjusted ERAInterim data and for instance the well-used WFDEI dataset (WATCH Forcing Dataset for ERA-Interim, developed by Weedon et al., 2014) are displayed and discussed. A key outcome of this assessment is that since there are a number of observational datasets that represent reality, it is vital to clearly state which is used in any bias-adjustment applications.

\footnotetext{
${ }^{4}$ These are provided within the bias adjusted gridded products: where gaps in observations exist the default we adopted is to use original ERA-Interim data.
}

These bias-adjusted ECV time series, together with the original PSL and SD, have been made available through the C3S ECEM Demonstrator: http://ecem.climate.copernicus. eu/demonstrator/ (last access: 3 July 2018). While the main ECV products displayed on the C3S ECEM Demonstrator are country and cluster averages, the $0.5^{\circ}$ by $0.5^{\circ}$ resolution gridded data are also made available through the C3S ECEM ftp site (ftp://ecem.climate.copernicus.eu/, last access: 3 July 2018), with complete details (including all the data processing of ERA-Interim and the observational datasets with which this was compared in Jones et al., 2017).

As described in Jones et al. (2017), the bias-adjusted ECVs were produced assuming that the variables were independent of one another (univariate bias adjustment). However, in C3S ECEM a bi-variate bias adjustment was considered too. This work concluded that bias adjustment becomes harder for more than two variables and becomes more complex if bias adjustment of climate change projections is contemplated as questions of non-stationarity arise (Dekens et al., 2017). The problems are not insurmountable but require further study, beyond this particular project.

\section{Seasonal prediction period}

The energy sector has been identified as a key potential user of seasonal climate prediction services (e.g. Troccoli, 2010; Buontempo et al., 2010; Brayshaw et al., 2011; Bruno Soares 
and Dessai, 2015). However, the skill of seasonal forecasts must be assessed and understood before forecasts can be provided. We have therefore looked in detail at the skill of current seasonal forecast systems in predicting quantities relevant to the energy sector for the C3S ECEM project.

In recent years, different seasonal forecasting systems have demonstrated sufficient skill over Europe to justify the development of prototype and operational services in various sectors (e.g. De Felice et al., 2015; Svensson et al., 2015; Mackay et al., 2015; Palin et al., 2016; Viel et al., 2016; Clark et al., 2017). The skill of a forecasting system is assessed using retrospective forecasts, i.e. forecasts of past seasons made using the current forecasting system. The accuracy of the skill assessments is limited by features of those retrospective forecast data sets, such as the number of years they cover and the size of the forecast ensembles produced each season.

Forecast skill can be assessed through a wide range of different statistics, each of which probe different aspects of the forecasts with different levels of detail (see e.g. Wilks, 2011; Jolliffe and Stephenson, 2012). For the C3S ECEM project, we have focused on the simple Pearson correlation between the ensemble-mean retrospective forecasts and the bias-adjusted historical data (described above). This is often seen as a measure of deterministic skill, although using the ensemble means (enhancing the detectable forecast signal by reducing the noise from the ensemble) can provide an indication of the skill of probabilistic forecasts (Palin et al., 2016; Bett et al., 2018a). We have also assessed more directlyprobabilistic statistics, looking at reliability and ROC diagrams, and their corresponding Brier and ROC skill scores (Wilks, 2011; Jolliffe and Stephenson, 2012).

We have performed a preliminary skill assessment of the climate variables described above, using the retrospective forecast data sets available from ECMWF as part of the EUROSIP multi-model seasonal forecasting system: from ECMWF (Molteni et al., 2011), Météo-France (Voldoire et al., 2013), and the Met Office (MacLachlan et al., 2015). For the final C3S ECEM Demonstrator, we will be using new seasonal retrospective forecast data available from the $\mathrm{C} 3 \mathrm{~S}$ Climate Data Store, which is being developed in parallel to C3S projects like ECEM.

Using three different dynamical forecasting systems, based on different coupled climate models, provides a good overview of the current status of seasonal forecasting skill. It is important to appreciate that the skill will not only differ between models, but will also vary considerably between different variables, seasons and regions. As the seasonal retrospective forecast data is generally available at $1^{\circ}$ horizontal resolution, rather than the $0.5^{\circ}$ of the historical data, we have restricted our assessments to European countries, rather than clusters. Assessing skill directly at the European country scale, across Europe, is a novel feature of the C3S ECEM project, and one that closely scrutinises the forecast systems and their retrospective forecast data sets. It is more common to assess seasonal forecasts at the scale of Europe as a whole, particularly in terms of reliability (e.g. Molteni et al., 2011; Weisheimer and Palmer, 2014).

Our main findings are that levels of skill vary considerably across the different models, variables, seasons and countries considered. This means that seasonal forecasts have to be used carefully and selectively. Skill in winter is very diverse across the models and variables we assess. In summer, the three models are more consistent in which areas can be forecast skilfully, although there are fewer cases of significant skill overall. It is important to note however that we have examined the direct model output for each climate variable. This provides a simple baseline assessment of skill, and more sophisticated techniques, for example using knowledge of larger-scale climate drivers, could yield more skilful bespoke forecasts for particular regions. Subsequent work on seasonal forecasting within the C3S ECEM project will examine different methods of forecasting energy supply and demand metrics, focusing on the cases where we have found significant skill in forecasting their corresponding climate variables.

The seasonal skill assessments are described in detail in technical reports made available as part of the user guidance on the C3S ECEM Demonstrator (Bett et al., 2018b). The Demonstrator itself provides maps of country-level skill across Europe, as well as time series for each country showing the relationship between the historical data and the retrospective forecast ensemble means.

\section{Projection period}

Climate change projections used in C3S ECEM have been derived from Global Climate Models (GCMs) and Regional Climate Model (RCMs). GCMs are available from the CMIP5 (fifth Coupled Model Inter-comparison Project) ensemble of simulations, but their spatial resolution is relatively coarse. RCMs, which use GCMs (from CMIP5 in our case) as their boundary conditions, provide more detailed spatial resolution (comparable to our historical bias-adjusted datasets). In C3S ECEM, it was decided to base the projections on RCM output for our European domain, EUROCORDEX, rather than global climate projections. This is because:

- EURO-CORDEX provides a higher spatial and temporal resolution, typically one order of magnitude higher;

- Bias-adjustment of energy-related climate variables were already available through the Impact2C/C3S CLIM4ENERGY (C4E, http: //clim4energy.climate.copernicus.eu/, last access: 3 July 2018) project;

- Consistency in output relative to climate change projections from the two Energy Sectoral Information Systems (SISs, namely C3S ECEM and C4E) was considered a desirable outcome. 
Following EURO-CORDEX, output based on the two most common Representative Concentration Pathways (RCPs), RCP4.5 and RCP8.5, have been used in C3S ECEM. Since it would be useful to consider low-carbon scenarios from the EU perspective (as used in e.g. the e-Highway2050 project), it could be argued that also lower RCPs should be considered, as for instance RCP2.6. One issue is that output from EURO-CORDEX for RCP2.6 is sparse, and it would not therefore be possible to meaningfully compare this output with that of RCP4.5 and RCP8.5. In any case, the two RCPs considered here provide a useful reference for other RCPs.

Data from both the GCMs and RCMs are available via the Earth System Grid Federation (ESGF). Over ten RCM simulations are available for the European domain, but some are closely-related variants of other simulations, so less useful than simulations which are more independent of each other. $\mathrm{C} 4 \mathrm{E}$ assessed this similarity and independence, together with the model skill, and determined the best choices of GCM and RCM configurations to use if resources were only available to work with seven, five or three. The rationale behind the $\mathrm{C} 4 \mathrm{E}$ choices is that the main determinant driving the variability within an RCM is the underlying GCM providing the boundary conditions. Their choices of 3 and 5 all contain different driving GCMs. For further detail please see $\mathrm{C} 4 \mathrm{E}$ report Climate projection dataset release for the energy sector ${ }^{5}$. In C3S ECEM we chose to use the 7-member sub-ensemble.

The C4E bias-adjusted variables (TA, TP, WS and GHI) were obtained from the relevant ESGF node ${ }^{6}$. These variables are listed under the project CORDEX-Adjust. The other variables (RH, MSL and SD) were obtained from the ESGF CORDEX repository ${ }^{7}$.

Data were extracted at the best temporal resolution available. This is generally 3 -hourly but for some variables it can be daily. The temporal resolution (together with GCM and RCM configuration, ECV and start and end dates) can be found in the corresponding Variable Fact Sheet (VFS) in the C3S ECEM Demonstrator. The data are available for the period from 1979-2100, and for the two RCPs (4.5 and 8.5). The switch between historic forcing and projections occurs at year 2005, so the first part of the simulations from 1979

\footnotetext{
${ }^{5}$ Available at: http://clim4energy.climate.copernicus.eu/ sites/default/files/C4E_ClimateProjection4Energy_dataset_v4_ summary.pdf (last access: 25 February 2018).

${ }^{6}$ https://esgf-node.ipsl.upmc.fr/search/c3s-energy/ (last access: 25 February 2018).

${ }^{7}$ https://esgf-data.dkrz.de/projects/esgf-dkrz/ (last access: 25 February 2018), (other nodes are also available). Note that C4E obtained the data for one of the CORDEX models directly from the model developer's as it is not in the CORDEX archive. This means that RH, MSL and SD are missing for this RCM. Also, for another model: RH was not available and SD was not used as it contained many small negative values. Given the issues with these SD projection data, these were not used in the Demonstrator in the end.
}

for the two RCPs are the same. The data from each RCM was re-gridded onto the standard C3S ECEM grid $\left(0.5^{\circ}\right.$ by $0.5^{\circ}$ latitude/longitude) and the C3S ECEM domain $\left(27^{\circ}-72^{\circ} \mathrm{N}\right.$ by $22^{\circ} \mathrm{W}-45^{\circ} \mathrm{E}$ ) was retained.

From the cluster and country averages, an ensemble mean has been calculated and is available for the monthly, seasonal and annual timescale. The variance of the ensemble mean time series is reduced compared to the individual RCM simulations (and also the historic series) due to higher-frequency variability in the RCMs not being in phase with one another. The RCMs have common external forcings (greenhouse gases, solar and some have aerosols) but the detailed time-evolution of each model (i.e. their internal variability) will differ depending on the equations and parameterisations used. Additionally, to give some idea of the RCM uncertainty, within the Demonstrator, we provide an upper and lower range (the highest and lowest RCM value for each time step, monthly, seasonal and annual) and plot a smoothed version to simplify their representation.

\section{Energy variables}

A substantial amount of work has gone into collecting and harmonising energy data from various sources including ENTSO-E $^{8}$, eHW2050, EUROSTAT ${ }^{9}$, World Bank, national Transmission System Operators (TSOs) data not contained in the ENTSO-e dataset ${ }^{10}$, the WindPower database ${ }^{11}$, data from EMHIRES ${ }^{12}$, and the Ninja project (Staffell and Pfenninger, 2016). These data have been critical in testing conversion models (from climate to energy variables) developed for the historical period, as described in this section, which are then applied for the seasonal forecast and projection pe$\operatorname{riod}^{13}$.

Based on a literature review, project partners' expertise and stakeholder interaction, the energy variables provided by C3S ECEM are:

- Electricity demand (DEM)

- Electricity supply from:

- Wind power generation (WPG) - Onshore only (data from offshore wind power is much less accessible, than for onshore; it is also less widespread than onshore)

\footnotetext{
${ }^{8}$ The European Network of Transmission System Operators for Electricity: https://www.entsoe.eu/ (last access: 25 February 2018).

${ }^{9} \mathrm{http}: / /$ ec.europa.eu/eurostat/data/database (last access: 25 February 2018).

${ }^{10} \mathrm{https}: / /$ transparency.entsoe.eu/ (last access: 25 February 2018).

${ }^{11} \mathrm{http}: / / \mathrm{www}$.thewindpower.net (last access: 25 February 2018).

${ }^{12}$ European Meteorological derived high resolution renewable energy source generation time series (https://ec.europa.eu/jrc/en/ scientific-tool/emhires last access: 25 February 2018).

${ }^{13}$ Most of the energy data presented in the following is available via the C3S ECEM Demonstrator.
} 
- Solar power generation (SPG) - PhotoVoltaic (PV) only (i.e. not Concentrating Solar Power, as this is less widespread than PV)

- Hydropower generation (HPG) - Run-of-the-River and Water Reservoir; pumped storage hydro power has not been considered given its little dependence on climate (since it is normally used for load balancing purposes, it mainly depends on human management factors).

It should be noted that only a very limited number of stakeholders requested information about bioenergy/biofuels, thermal and nuclear power generation. Although climate factors are less relevant for generation from thermal and nuclear power plants, climate variables like air or water temperature, relative humidity or river flow are used to determine the efficiency and availability of these plants' cooling systems. Thus, while C3S ECEM will not provide an estimation of thermal and nuclear generation as such, the climate variables provided by the Demonstrator provide useful indicators for these types of generation too.

The four main energy indicators - DEM, WPG, SPG and HPG - expressed as both power (in MW) and energy variables (in MWh), are being provided at country level, and whenever possible at daily time resolution (together with precomputed lower resolution averages, namely monthly, seasonal and annual). In addition, WPG, SPW and HPG are also provided as capacity factor (or load factor), that is the ratio of real generation to installed capacity (in the interval $[0$, 1]), providing the advantage that one can then easily compute generation with different installed capacity distributions.

Power generation can be calculated using either a statistical or a physical model. The difference is that, for statistical models, we build a relationship (model) between the cluster or country aggregated power generation and the climate variables, whereas, for physical models, we use a pre-defined relationship which provides the power output of a specific plant using the climate variables and characteristics of the generating plant (e.g. the power curve for a wind turbine). Statistical models are simpler to implement, as they require less information, but they need long-enough time series of energy generation to be calibrated. In contrast, the main advantage of physical models is that no power measurements are needed to compute the power output. They also have the extra advantage that they can be easily used with ECVs from climate projections or seasonal forecasts.

The methodologies used to calculate the energy variables provided by the C3S ECEM project are aimed at highlighting the role of climate on these energy variables. Thus, for instance, while DEM depends on many factors largely unrelated to climate (technological, social, etc.), in the C3S ECEM project great effort has been put into isolating the specific role that climate plays on DEM (as well as on the other energy variables taken into consideration). This is very important as it becomes easier to extrapolate in future projec- tions, or even at the seasonal time scale, climate-dependent DEM.

The detailed description of the energy conversion models developed by the C3S ECEM project for DEM, then hydro, solar and wind power generation is beyond the scope of this paper. These more specific papers are being written up, or are already available, as in the case of the solar PV conversion model (Saint Drenan et al., 2018). As mentioned, models are developed for the historical period and then applied to the projection period and the seasonal forecast period, but this is work in progress. In the following, brief details of each of these models - namely for DEM, WPG, SPG and HPG - are provided.

\section{Electricity demand model}

Based on EDF expertise, daily DEM is modelled using a regression approach, the Generalized Additive Model (GAM), a generalization of Linear Models. Introduced by Hastie and Tibshirani (1990), GAM has been improved by Wood (2006) and many others since then. This is a well known method for load forecasting (Pierrot and Goude, 2011; Fan and Hyndman, 2012; Goude et al., 2013), and has been successfully used in the Global Energy Forecasting Competition 2012 (GEFCOM2012) forecasting competition (Nédellec et al., 2014). Its major advantages are that it is simple to interpret, it is fast to run and it can be easily adapted to different datasets.

DEM is characterized by significant trends, due to population increase and economic activity variability. Across Europe, in particular, the 2008 financial crisis had noticeable impacts on energy demand. The DEM model is built therefore in two steps: (1) long term trend estimation and removal and (2) modelling of the daily residuals e.g. as undertaken in Thornton et al. (2016). The trend is then added to the daily model to reconstruct the whole signal. Models have been built using the climate variables that have an impact on DEM (temperature, wind speed, solar irradiation, relative humidity) according to industry experience, for country and daily averages. If for any reason one of the variables is not available, for seasonal forecasts or climate projections for instance, it is straightforward to remove that variable and rerun the models to take into account only the available climate variables.

For the historical ERA-Interim period, DEM is provided only at country level, as no information is available for the clusters' share of national values. In addition, DEM time series are provided in three different forms:

a. Full signal, including the long-term trend (see Fig. 3 for an example referring to four European countries);

b. Detrended signal, in which the time series is adjusted to the latest level, by removing the long-term trend;

c. Anomaly, in which the mean of (b) is removed, to isolate the climate dependant part of the signal 
ECEM time series: demand (DEM) energy (NRG)

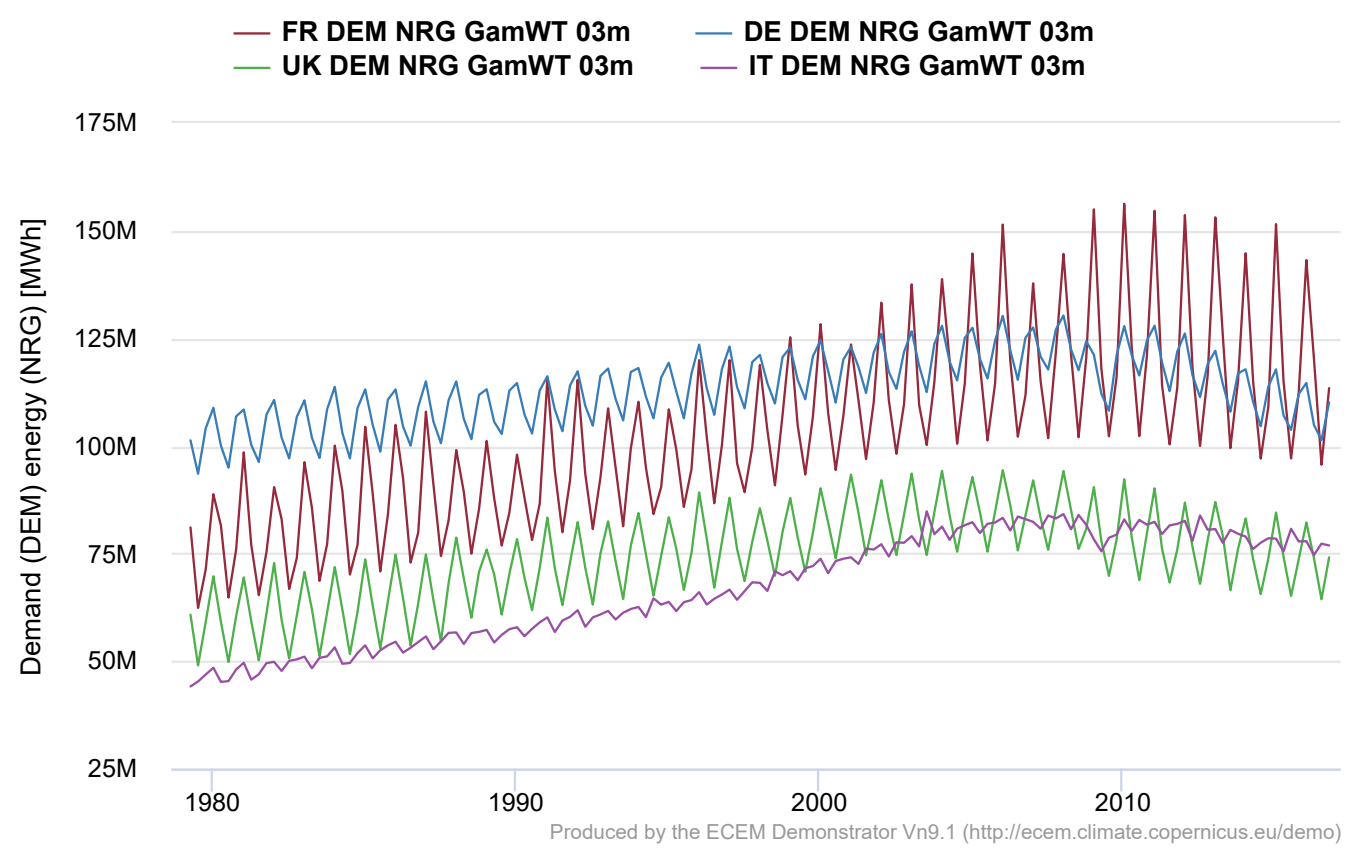

Figure 3. Example of seasonally averaged electricity demand (in MWh) plot for France (burgundy), Germany (blue), United Kingdom (green) and Italy (purple). This plot has been produced by, and downloaded from, the ECEM Demonstrator (http://ecem.climate.copernicus. eu/demonstrator/, last access: 3 July 2018).

\section{Hydro Power Generation model}

The data necessary to compute hydro-power using simple physical models (namely hydraulic head, plant location and plant efficiency; see e.g. van Vliet et al., 2016) are difficult to obtain. In France for instance, we managed to get these data only for about two thirds of the total hydropower installed capacity ( $15 \mathrm{GW}$ out of $24 \mathrm{GW}$ ). In other countries, data access is more complicated. Hydropower plant characteristics and generation data are indeed considered as strategic information by most energy companies, and hence is not shared publicly. As a consequence, it was decided that a more pragmatic approach was to model country-average HPG using statistical models. Separate models have been developed for run-of-the-river and water reservoir.

All the available variables (both for energy and meteorological aspects) have been aggregated at the daily level and calculated considering the national average. Not all the countries have been considered for this work. They have been chosen according to two aspects: (1) Generation data were available for at least 18 months; (2) Installed capacity of hydropower is among the countries with the largest installed generation capacities. The latter requirement has been introduced to focus the modelling work on the countries where hydropower generation plays an important role. According to these criteria, the countries analysed in this work are the following:
- Run-of-the-river for France, Austria, Germany, Finland, Portugal, Romania, Norway and United Kingdom

- Water reservoir for France, Austria, Germany, Portugal, Romania, Norway, Spain, Sweden and Switzerland

The most challenging aspect when modelling the hydropower generation using meteorological variables is the necessity to capture in some way the complex relationship between the availability of the water resource (obtained basically through precipitation and snow melting) and the production of electricity. Our assumption is that the generation at time $t$ is highly correlated not with the precipitation at the same time, but instead with the cumulative sum of the precipitation for the preceding $k$ days. So, the first step in our methodology is the search of the value of $k$ that maximises the Pearson correlation coefficient between the moving sum and the daily generation. After this step, the moving sum with the optimal $k$ is then included among the set of the predictors. The other used predictors are:

- Precipitation at time $t$

- Air temperature at time $t$

- Sum of the precipitation for the last 5 days

- Sum of the precipitation for the last 30 days 


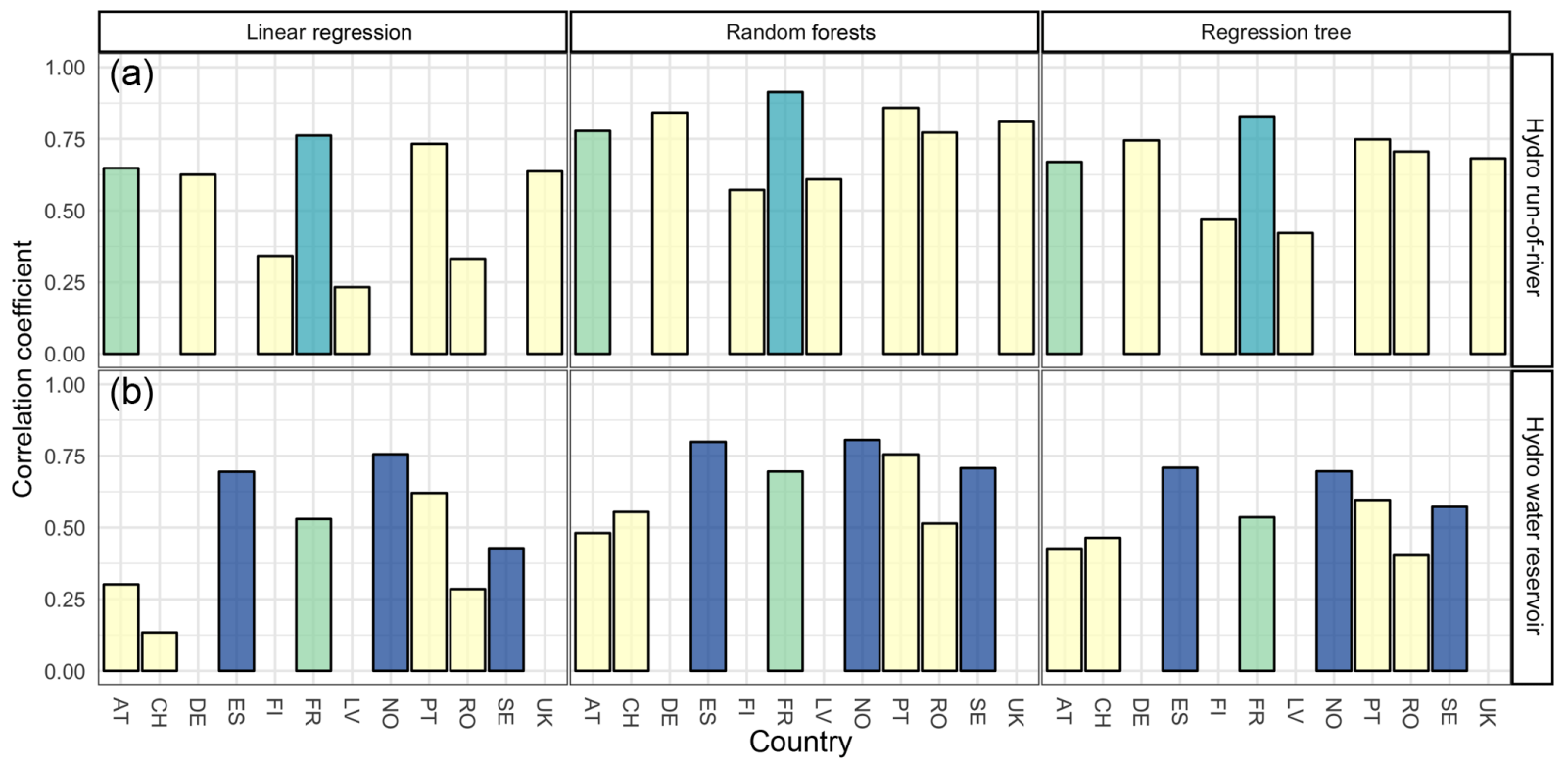

Installed capacity (GW) $\square<5 \square 5-10 \square 10-15 \square>15$

Figure 4. Correlation between prediction of country-average hydro power capacity factor using three statistical models (linear regression, random forests, regression tree) and measured data from the ENTSO-E dataset. (a) Run-of-River production. (b) Water Reservoir production. Country abbreviations are (in the order given): Austria (AT), Switzerland (CH), Germany (DE), Spain (ES), Finland (FI), France (FR), Latvia (LV), Norway (NO), Portugal (PT), Romania (RO), Sweden (SE), United Kingdom (UK).

Note that air temperature is used as proxy for snow depth (or snow melt) because the latter variable is not modelled with sufficient accuracy, particularly for projections or, even seasonal forecasts. Also, to provide a consistent and meaningful methodology we do not consider as a target variable (i.e. the predictand) directly the generated electricity but instead the capacity factor.

Three different statistical models have been tested: linear regression, random forests and regression tree. All the models have been calibrated and tested for each selected country and hydro-power type. A 10-fold cross-validation procedure has been applied. Figure 4 shows that this approach, while relatively simple, yields satisfactory results. Our extensive tests show that the random forests model yields a better performance than the other two models. Hence, only the random forests model is used for the C3S ECEM hydropower products. Further details about the hydro power modelling and additional results are available in De Felice et al. (2018).

\section{Solar Power Generation model}

In C3S ECEM PV power production is estimated by taking the aggregated power production of all plants included in each for each $0.5^{\circ}$ by $0.5^{\circ}$ cell. We used only a physical modelling approach for PV. This relies on some known characteristics of PV panels. A difficult issue in this calculation is the consideration of the characteristics of the PV plants (module orientation, technology...), which are only partially known in the past and present and difficult to assess in the future. The impact of most of these individual characteristics on the PV power generation is not negligible (Saint-Drenan, 2015). Therefore, a compromise has to be found in the choice of the power operator between an accurate model and an easy implementable approach.

Three different model formulations are proposed by Jerez et al. (2015) for the calculation of time series of PV power generation for climate projection. They can be summarized in the general expression given in Eq. (1):

$P_{\mathrm{pv}}=\mathrm{PR} \frac{G}{G_{\mathrm{STC}}}$

where $G$ is the downward short-wave (solar) radiation at the surface, $G_{\mathrm{STC}}$ is $G$ under standard test conditions and PR is the performance ratio of the PV plant.

The three variants of the model formulations differ in the expression of the performance ratio, which is assumed constant, depending on the irradiance and temperature and depending on the wind speed, irradiance and temperature in the first, second and third formulations respectively. The strength of the set of models proposed by Jerez et al. (2015) is that it requires a very limited amount of information to be implemented. A major drawback is however that, since the influence of the module orientation angles on the output power is neglected, the daily and seasonal variation of the PV power generation can noticeably differ from actual PV production. 
In C3S ECEM, an improved model was implemented based on the work of Saint-Drenan (2015) and Saint-Drenan et al. (2017), in which the total PV power produced in a region is calculated from meteorological data using a physical model. In this model, the characteristics of PV plants such as module orientation angles and power curve are first evaluated on the basis of a statistical analysis of a database containing meta-information of several thousands of PV plants. Assumptions about the installed PV capacity are necessary to aggregate the PV power generation evaluated for each cell in order to compare the model output with TSO data at country level. The model was trained over Germany and tested over France. For Germany, a database of more than 1.5 million PV plants has been used. For France, the information provided on a yearly basis on the total PV capacity installed on each of the more than 36000 French zip-code areas has been collected. With these datasets, the installed PV capacities have been calculated for each cell. The result of this PV modelling approach is displayed in Fig. 5. Our PV model was then applied to all other European countries considered in the C3S ECEM project and outputs are available on the Demonstrator. Further details about the solar power modelling and additional results are available in Saint-Drenan et al. (2018).

\section{Wind Power Generation model}

Wind power modelling in C3S ECEM has been performed using both physical and statistical models, with the two intercompared in order to select the approach with the more accurate representation of wind power capacity factor. The physical model computes the capacity factor by adopting the standard conversion relationship (e.g. Brayshaw et al., 2011) tested for several wind turbine types and several hub heights. Computing the capacity factor at individual wind farm level requires:

a. Improving the estimation of individual turbine height when not available in the WindPower database; this has been done by using the closest windfarm data (closest in terms of distance and commissioning date);

b. Improving the choice of power curves for individual farms; an analysis has been carried out to identify the most frequent turbine types as a function of the hub height, and a selection has been made to use different power curves associated to the hub height.

The statistical models have been trained using the most recent WPG data from the ENTSO-E transparency platform, for all the available countries. Two regression approaches have been compared: random forests and support vector machine.

The different options have been tested for France and some other countries for which at least daily time series of observed WPG is available for validation. It has to be noted that statistical models require such observations to be trained.
Therefore, as this kind of data is not available for all countries, it is not possible to implement the statistical approach everywhere. Our WPG data, using both physical and statistical models, have been compared also with the EMHIRES data set (Gonzales Aparicio et al., 2016) and with the Ninja data set (Staffel and Pfenninger, 2016) as displayed in Fig. 6. Further details about the wind power modelling and additional results are available in Dubus et al. $(2017,2018)$.

\section{Stakeholder engagement}

The C3S ECEM programme of stakeholder engagement has provided a wealth of information and feedback via workshops, one-to-one meetings with experts, advisory committee interaction, email surveys, webinars and interactions at key conferences and seminars. While keeping the communication methods and suite of communication tools largely unchanged, a key aspect of the C3S ECEM approach to stakeholder engagement is that it has continually been adapted to suit the broadening stakeholder groups. Also, joint stakeholder engagement in the form of a Climate and Energy Symposium $^{14}$ in February 2017 with the sister C3S C4E project has allowed us to draw on expertise to complement both the energy Demonstrator tools whilst reaching a wider audience.

Stakeholder workshops have played a strong role in eliciting input from a wide and diverse audience towards the development of the Demonstrator. Four workshops, one every six months, have been held by the C3S ECEM project at different locations around Europe, also as a way to attract different regional audiences. The broad objectives of the C3S ECEM workshops have been:

- To engage with a wide number of energy sector experts (industry, policy, service providers, academia) to seek their views on requirements for climate services;

- To elicit feedback on the Demonstrator and the climate and energy data it provides, through "hands-on" participation sessions;

- To allow prospective users to discover through case studies how access to climate information can improve an organisation's ability to cope with extreme climate events and scenarios, and to build a simple tailored data assessment;

As such, the C3S ECEM stakeholder workshops have been carefully planned to ensure these objectives were achieved in the most effective way. Indeed, the approach taken in each workshop has considered the expected audience and, especially, the level of progress of the project and of the C3S ECEM Demonstrator. For instance, in the first workshop (February 2016), when the visual component of the Demonstrator was still in an embryonic stage, stakeholders provided

\footnotetext{
${ }^{14} \mathrm{http} / / /$ limate.copernicus.eu/events/copernicus-symposiumclimate-services-energy-sector (last access: 3 July 2018).
} 

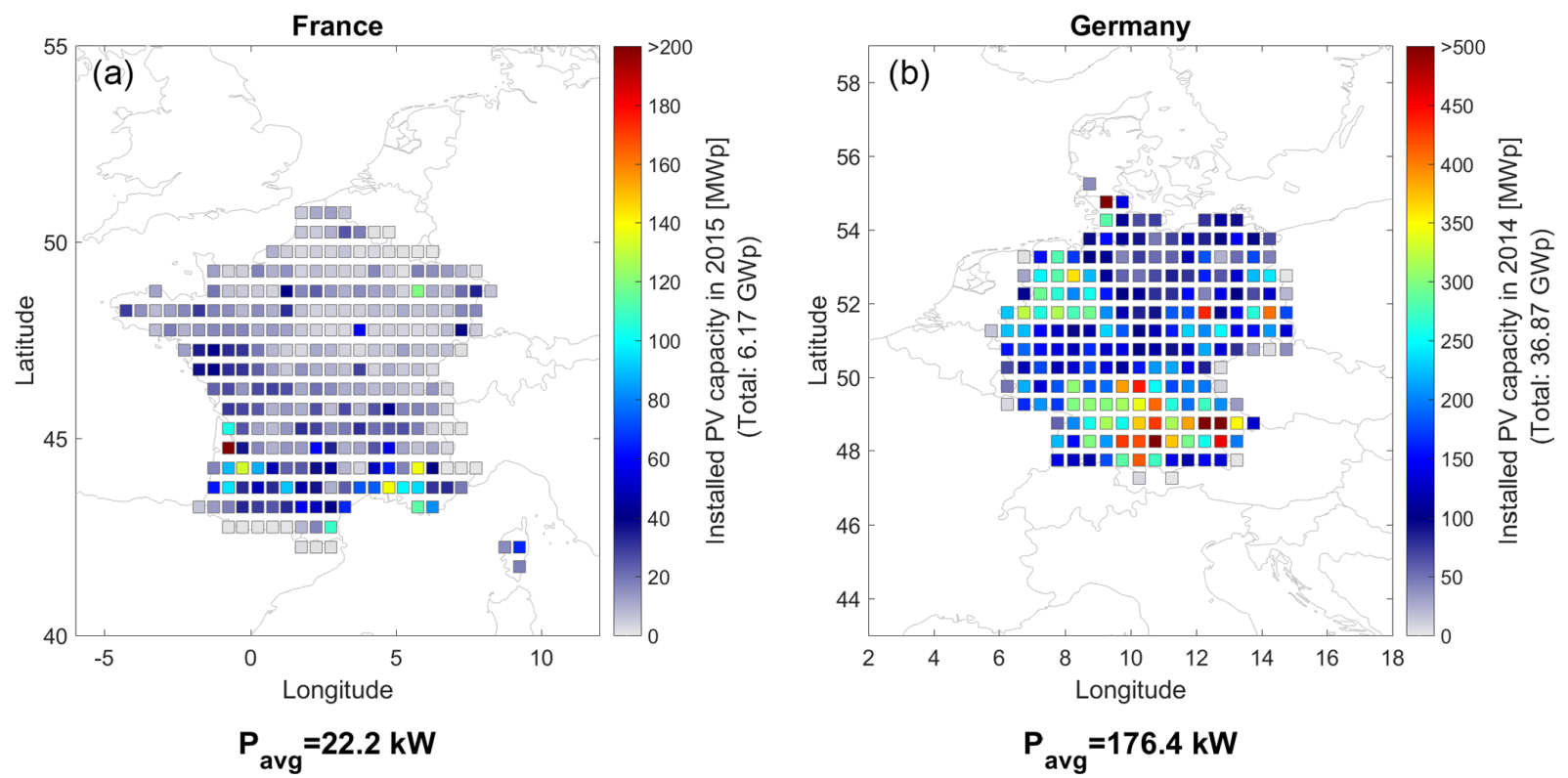

Figure 5. Spatial distribution of the installed PV capacity in France (a) and Germany (b) considering the actual spatial distribution of the installed capacity. Note that the scales in the two panels are different.

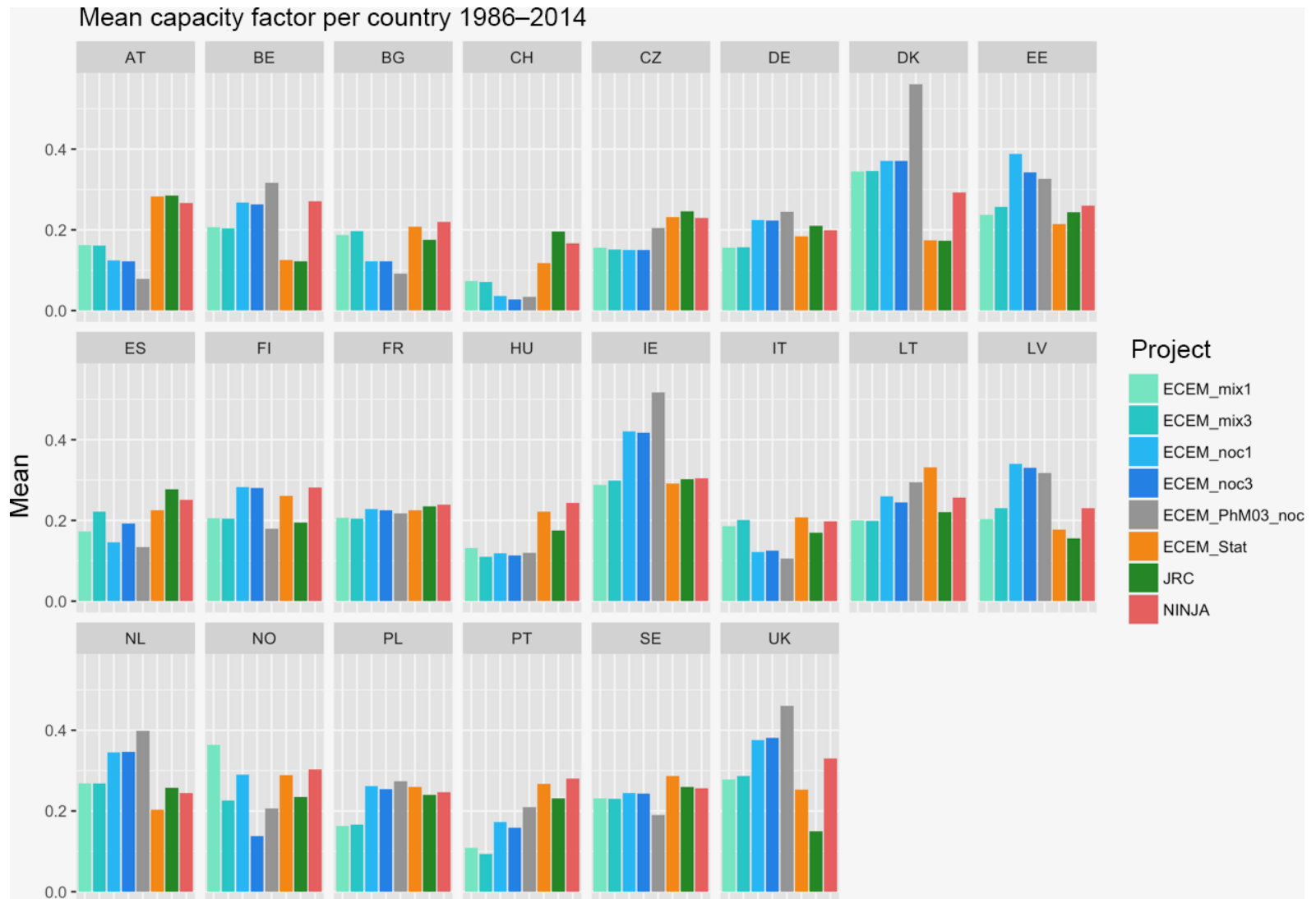

Figure 6. Country-average wind power capacity factor for C3S ECEM wind power models, and JRC (EMHIRES, green) and Ninja (salmon) datasets. In model mixl and nocl the known installed capacities from the WindPower database were used; in mixl a mix of bias-adjusted $100 \mathrm{~m}$ wind speed were used (i.e. bias-adjusted over land and non-bias-adjusted over the ocean), in model nocl the original ERA-I extrapolated to $100 \mathrm{~m}$ wind speed were used. In PhM03_wbc, the bias-adjusted $100 \mathrm{~m}$ wind speed data were applied to a fixed wind turbine type at each $0.5^{\circ}$ by $0.5^{\circ}$ grid cell. Finally, Stat is the statistical model using the support vector machine approach. 
Table 1. Energy and climate sector requirements now and in the future.

\begin{tabular}{ll}
\hline User Category & User requirement \\
\hline Energy producing companies & $\begin{array}{l}\text { Energy planners require data and modelling tools (Multi-decadal climate } \\
\text { change projections) to prioritise investment initiatives }\end{array}$ \\
\hline $\begin{array}{l}\text { TSOs and Distribution System } \\
\text { Operators (DSOs) }\end{array}$ & $\begin{array}{l}\text { Requirement for bias adjusted climate data and energy supply and demand data. } \\
\text { Some organisations use in house modelling tool to check supply will meet de- } \\
\text { mand on a seasonal basis and on a multi-decadal timeframe for infrastructure } \\
\text { decisions. }\end{array}$ \\
\hline $\begin{array}{l}\text { International Organisations and } \\
\text { Projects }\end{array}$ & $\begin{array}{l}\text { Requirement for bias adjusted climate data and energy supply and demand data. } \\
\text { Would potentially use Demonstrator for forecasting, particularly at country and }\end{array}$ \\
\hline $\begin{array}{l}\text { Policy and operational relevant } \\
\text { research organisations }\end{array}$ & $\begin{array}{l}\text { Requirement for multi-decadal climate change projections. Would potentially } \\
\text { use Demonstrator for devising and advising investment and infrastructure deci- } \\
\text { sions at cluster, country and pan-European level. }\end{array}$ \\
\hline
\end{tabular}

abundant input to help shape it, including via users' stories. In workshop three (jointly delivered with C3S C4E), we canvassed stakeholder feedback through a series of breakout group discussions and plenary summaries. With the fourth workshop, we showcased the Demonstrator and arranged for groups to select and build on a case study of their choice. In so doing we captured comments and feedback from the different categories of user present. A programme of webinars, to present the various aspects of the C3S ECEM project, from the work on climate variables, to energy variables and to the Demonstrator, has formed an integral component of stakeholder engagement, with feedback gathering and information sharing as their main aims. A number of "learning" areas for C3S ECEM have thus been achieved: energy and climate sector characteristics, communication with key stakeholders, as well as the technical requirements of potential users. For instance, our engagement activities have helped define energy and climate sector requirements now and in the future, as summarised in Table 1.

While our stakeholder engagement activities targeted a large number of prospective users, the project also benefited strongly from having an industrial partner (EDF) directly involved in the project execution, rather than as an external stakeholder. EDF participation has not only allowed the project to benefit from direct and continuous feedback on the development of the Demonstrator, but has also led to the development of key methodologies for analysing and working with energy variables, using the expertise of EDF professionals.

\section{The Demonstrator: the visible part of the iceberg}

As mentioned throughout this paper, the ultimate target of the C3S ECEM project has been the development of the C3S ECEM Demonstrator. This is an interactive visual on-line tool, which allows users to view and explore energy supply and demand profiles, and climate variables, for each European country and subnational cluster, in map and time series format (Fig. 2). As discussed, the C3S ECEM Demonstrator has been developed in accordance with user needs, and integrates the energy and climate variable data produced in C3S ECEM on historical, seasonal forecasting and future climate projection timescales. Time series and map data for countries and clusters can also be downloaded directly from the Demonstrator, whereas bulkier gridded data, in the form of netCDF files, are available through the project ftp server, which is also readily accessible via the Demonstrator.

The C3S ECEM Demonstrator has been designed to be relatively simple, with pre-calculated data displayed as both maps and time series plots, while allowing for interactive changes to plotted maps and time series. Although the horizontal resolution displayed is not as high as the original underlying gridded data, the visual simplicity of the C3S ECEM Demonstrator makes it accessible to climate and energy specialists (to carry out initial investigations) and to less experienced users such as policy makers or even high-school students.

A wide variety of help and guidance is provided with the Demonstrator, including key messages and event case studies which illustrate the types of information that the Demonstrator offers, and how it can be used and interpreted to benefit the energy sector. Documentation (including variable fact sheets) is provided on all the data sets embedded in the Demonstrator to ensure transparency and that users have appropriate information to judge the quality and reliability of these data for their own particular applications.

It is important to note that in order to handle the large amount of data and files generated by the C3S ECEM Demonstrator, conventions were discussed and agreed as pre- 
sented in the C3S ECEM Data Management Plan ${ }^{15}$. Such conventions will be key elements in the development of any future operational phase of the service.

While the Demonstrator functionality is intended to be broadly frozen during the current pre-operational phase, feedback is continually encouraged, for instance though the feedback tab on the right-hand-side of the Demonstrator page. Interested prospective users of the C3S Demonstrators are therefore encouraged to regularly visit the project and Demonstrator web pages, and to test the Demonstrator: http://ecem.climate.copernicus.eu/ demonstrator/ (last access: 3 July 2018). Feedback will be gratefully received.

\section{Conclusions and perspectives}

The Demonstrator has been promoted and demonstrated at various venues, including the European Meteorological Society Conference in September 2017 in Dublin. It is now available for public access and users are encouraged to explore and exploit it, and to provide ongoing feedback. A number of new features, such as energy variables at the climate projection time scale, are being produced for inclusion in the Demonstrator. Energy companies and operators, such as TSOs, and energy policy makers will benefit from the codesigned climate service Demonstrator as it will provide a set of tools to better assess energy mix options over Europe. Importantly, by bringing together climate and energy data for different time frames - historical, seasonal forecasting and future projections - that are consistent in space and time, well documented, and easy accessible, the C3S ECEM Demonstrator will:

- Ensure that estimates of the country energy mixes properly reflect climate conditions including their variability, and it will therefore allow end-users to better assess the optimal supply mix that can meet demand in the most cost effective manner;

- Offer a coherent approach for the climate variables and energy indicators used in power demand and supply balance, an added value with respect to current practice in the sector, where climate data and derived energy variables are not always physically homogeneous and/or in balance

As well as providing a critical building block for an operational energy service, we envisage that the Demonstrator and its associated data sets could be used in a variety of future research projects (such as European H2020 projects), as it offers a unique approach: it provides a Europe-wide, multivariable, multi-timescale view of the climate and energy sys-

\footnotetext{
${ }^{15}$ An abridged version can be downloaded at: ftp://ecem. climate.copernicus.eu/C3S_ECEM_README_v1.pdf (last access: 3 July 2018).
}

tems. It can therefore help in anticipating important climatedriven changes in the energy sector, through either long-term planning or medium-term operational activities. For instance, it can be used to investigate the role of temperature on electricity demand across Europe, as well as its interaction with the variability of renewable energies generation.

Data availability. The data produced by the EU Copernicus Climate Change Service (C3S) European Climatic Energy Mixes (ECEM) is available through its Demonstrator which can be accessed via the http://ecem.wemcouncil.org. The C3S website (https: //climate.copernicus.eu/) also contains complementary and/or more updated information.

Author contributions. AT drafted most of the manuscript with specific contributions from LW for Sect. 1, CG, PJ, SD, CH, SP, PEB, HT, LW, ES and DB for Sect. 2, LD, SC, DHK, YMSD and MDF for Sect. 3, CG, LP and TR for Sect. 4, CG, LD, BP and JB for Sect. 5. Most authors reviewed the manuscript and provided comments to the whole manuscript.

Competing interests. The authors declare that they have no conflict of interest.

Special issue statement. This article is part of the special issue "17th EMS Annual Meeting: European Conference for Applied Meteorology and Climatology 2017”. It is a result of the EMS Annual Meeting: European Conference for Applied Meteorology and Climatology 2017, Dublin, Ireland, 4-8 September 2017.

Acknowledgements. The authors would like to acknowledge funding for the European Climatic Energy Mixes (ECEM) project by the Copernicus Climate Change Service (C3S), a programme being implemented by the European Centre for Medium-Range Weather Forecasts (ECMWF) on behalf of the European Commission (grant number: 2015/C3S_441_Lot2_UEA).

Edited by: Dick Dee

Reviewed by: John Dutton and one anonymous referee

\section{References}

Becker, A., Finger, P., Meyer-Christoffer, A., Rudolf, B., Schamm, K., Schneider, U., and Ziese, M.: A description of the global land-surface precipitation data products of the Global Precipitation Climatology Centre with sample applications including centennial (trend) analysis from 1901-present, Earth Syst. Sci. Data, 5, 71-99, https://doi.org/10.5194/essd-5-71-2013, 2013.

Bett, P. E., Scaife, A. A., Li, C., Hewitt, C., Golding, N., Zhang, P., Dunstone, N., Smith, D. M., Thornton, H. E., $\mathrm{Lu}$, R., and Ren, H.-L.: Seasonal forecasts of the summer 
2016 Yangtze River basin rainfall, Adv. Atmos. Sci., in press, https://doi.org/10.1007/s00376-018-7210-y, 2018a.

Bett, P. E., Thornton, H., and Troccoli, A.: Skill assessment of energy-relevant climate variables in a selection of seasonal forecast models, ECEM Deliverable report D2.2.1, version 2, 57 pp., available at: http://ecem.wemcouncil.org/pdf/C3S_441_Lot2_ECEM_ D2.2.1_201701_SeasonalSkillAssessementOfECVs_v2.pdf (last access: 3 July 2018), 2018b.

Bloomfield, H. C., Brayshaw, D. J., Shaffrey, L. C., Coker, P. J., and Thornton, H. E.: Quantifying the increasing sensitivity of power systems to climate variability, Environ. Res. Lett., 11, 17489326, https://doi.org/10.1088/1748-9326/11/12/124025, 2016.

Bojinski, S., Verstraete, M., Peterson, T. C., Richter, C., Simmons, A., and Zemp, M.: The concept of essential climate variables in support of climate research, applications, and policy, B. Am. Meteorol. Soc., 95, 1431-1443, https://doi.org/10.1175/BAMS-D13-00047.1, 2014.

Brayshaw, D. J., Troccoli, A., Fordham, R., and Methven, J.: The impact of large scale atmospheric circula on patterns on wind power genera on and its potential predictability: A case study over the UK, Renew. Energ., 36, 2087-2096, https://doi.org/10.1016/j.renene.2011.01.025, 2011.

Bruno Soares, M. and Dessai, S.: Exploring the use of seasonal climate forecasts in Europe through expert elicitation, Clim. Risk. Manage., 10, 8-16, https://doi.org/10.1016/j.crm.2015.07.001, 2015.

Buontempo, C., Brookshaw, A., Arribas, A., and Mylne, K.: MultiScale projections of weather and climate at the UK Met Office, in: Management of Weather and Climate Risk in the Energy Industry, NATO Science for Peace and Security Series C: Environmental Security, edited by: Troccoli, A., chap. 3, 39-50, Springer Netherlands, Dordrecht, https://doi.org/10.1007/97890-481-3692-6_3, 2010.

C3S: Copernicus Climate Change Service (C3S), a programme operated by the European Centre for Medium-Range Weather Forecast (ECMWF) on behalf of the European Union, available at: https://climate.copernicus.eu/, last access: 15 August 2018.

C3S ECEM: Copernicus Climate Change Service (C3S) European Climatic Energy Mixes (ECEM), The ECEM Demonstrator, available at: http://ecem.wemcouncil.org, last access: $15 \mathrm{Au}-$ gust 2018

Clark, R. T., Bett, P., Thornton, H., and Scaife, A.: Skilful seasonal predictions for the European energy industry, Environ. Res. Lett., 12, 024002, https://doi.org/10.1088/1748-9326/aa57ab, 2017.

Compo, G. P., Whitaker, J. S., Sardeshmukh, P. D., Matsui, N., Allan, R. J., Yin, X., Gleason Jr., B. E., Vose, R. S., Rutledge, G., Bessemoulin, P., Brönnimann, S., Brunet, M., Crouthamel, R. I., Grant, A. N., Groisman, P. Y., Jones, P. D., Kruk, M. C., Kruger, A. C., Marshall, G. J., Maugeri, M., Mok, H. Y., Nordli, Ø., Ross, T. F., Trigo, R. M., Wang, X. L., Woodruff, S. D., and Worley, S. J.: The twentieth century reanalysis project, Q. J. Roy. Meteor. Soc., 137, 1-28, https://doi.org/10.1002/qj.776, 2011.

Dee, D. P., Uppala, S. M., Simmons, A. J., Berrisford, P., Poli, P., Kobayashi, S., Andrae, U., Balmaseda, M. A., Balsamo, G., Bauer, P., Bechtold, P., Beljaars, A. C. M., van de Berg, L., Bidlot, J., Bormann, N., Delsol, C., Dragani, R., Fuentes, M., Geer, A. J., Haimberger, L., Healy, S. B., Hersbach, H., Hólm, E. V., Isaksen, L., Kållberg, P., Köhler, M., Matricardi, M., McNally,
A. P., Monge-Sanz, B. M., Morcrette, J.-J., Park, B.-K., Peubey, C., de Rosnay, P., Tavolato, C., Thépaut, J.-N., and Vitart, F.: The ERA-Interim reanalysis: configuration and performance of the data assimilation system, Q. J. Roy. Meteor. Soc., 137, 553-597, https://doi.org/10.1002/qj.828, 2011.

De Felice, M., Alessandri, A., and Catalano, F.: Seasonal climate forecasts for medium-term electricity demand forecasting, Appl. Energ., 137, 435-444, https://doi.org/10.1016/j.apenergy.2014.10.030, 2015.

De Felice, M., Dubus, L., Suckling, E., and Troccoli, A.: The impact of the North Atlantic Oscillation on European hydropower generation, Appl. Energ., submitted, preprint available at: https://eartharxiv.org/8sntx/ (last access: 3 July 2018), 2018.

Dekens, L., Parey, S., Grandjacques, M., and Dacunha-Castelle, D.: Multivariate distribution correction of climate model outputs: A generalization of quantile mapping approaches, Environmetrics, 28, 1-19, 2017.

Dubus, L., De Felice, M., Claudel, S., Saint-Drenan, Y.-M., Troccoli, A., Goodess, C., Zhang, S., Ranchin, T., and Thornton, H.: The ECEM climate service: how reanalysis can help energy planning, EMS Annual Meeting 2017, Dublin, Ireland, 4-8 September 2017, Abstract EMS2017-822, 2017.

Dubus, L., Claudel, S., De Felice, M., Saint-Drenan, Y.-M., and Troccoli, A.: A new dataset of power demand and supply over Europe, in preparation, 2018.

e-Highway2050 (e-HW2050): Europe's future secure and sustainable electricity infrastructure, Final project report, available at: http://www.e-highway2050.eu/fileadmin/documents/e_ highway2050_booklet.pdf (last access: 25 February 2018), 2015.

Fan, S. and Hyndman, R. J.: Short-term load forecasting based on a semi-parametric additive model, IEEE T. Power Syst., 27, 134141, 2012.

Frankel, D. and Wagner, A.: Battery storage: The next disruptive technology in the power sector, A McKinsey \& Company publication, available at: https://www.mckinsey.com/businessfunctions/sustainability-and-resource-productivity/ourinsights/battery-storage-the-next-disruptive-technology-inthe-power-sector (last access: 25 February 2018), 2017.

Gonzales Aparicio, I., Zucker, A., Careri, F., Monforti, F., Huld, T., and Badger, J.: EMHIRES dataset, Part I: Wind power generation, JRC Science for policy report JRC103442, European Union, 73 pp., https://doi.org/10.2790/831549, 2016.

Goude, Y., Nedellec, R., and Kong, N.: Local Short and Middle term Electricity Load Forecasting with semi-parametric additive models, IEEE T. Smart Grid, 5, 440-446, 2013.

Harris, I., Jones, P. D., Osborn, T. J., and Lister, D. H.: Updated high-resolution monthly grids of monthly climatic observations: the CRU TS 3.10 dataset, Int. J. Climatol., 34, 623-642, https://doi.org/10.1002/joc.3711, 2014.

Hastie, T. and Tibshirani, R.: Generalized additive models, Chapman \& Hall, London, 1990.

Haylock, M. R., Hofstra, N., Klein Tank, A. M. G., Klok, E. J., Jones, P. D., and New, M.: A European daily high-resolution gridded dataset of surface temperature and precipitation, J. Geophys. Res., 113, D20119, https://doi.org/10.1029/2008JD010201, 2008.

Jerez, S., Tobin, I., Vautard, R., Montávez, J. P., López-Romero, J. M., Thais, F., Bartok, B., Christensen, O. B., Colette, A., Déqué, M., Nikulin, G., Kotlarski, S., van Meijgaard, E., Teich- 
mann, C., and Wild, M.: The impact of climate change on photovoltaic power generation in Europe, Nat. Commun., 6, 10014, https://doi.org/10.1038/ncomms10014, 2015.

Jolliffe, I. T. and Stephenson, D. B. (Eds.): Forecast Verification: A Practitioner's Guide in Atmospheric Science, 2nd edn., John Wiley \& Sons, Ltd, Chichester, UK, https://doi.org/10.1002/9781119960003, 2012.

Jones, P. D., Harpham, C., Troccoli, A., Gschwind, B., Ranchin, T., Wald, L., Goodess, C. M., and Dorling, S.: Using ERA-Interim reanalysis for creating datasets of energyrelevant climate variables, Earth Syst. Sci. Data, 9, 471-495, https://doi.org/10.5194/essd-9-471-2017, 2017.

Kobayashi, S., Ota, Y., Harada, Y., Ebita, A., Moriya, M., Onoda, H., Onogi, K., Kamahori, H., Kobayashi, C., Endo, H., Miyaoka, K., and Takahashi, K.: The JRA-55 Reanalysis: General Specifications and Basic Characteristics, J. Meteorol. Soc. Japan, 93, 5-48, https://doi.org/10.2151/jmsj.2015-001, 2015.

MacLachlan, C., Arribas, A., Peterson, K. A., Maidens, A., Fereday, D., Scaife, A. A., Gordon, M., Vellinga, M., Williams, A., Comer, R. E., Camp, J., Xavier, P., and Madec, G.: Global Seasonal forecast system version 5 (GloSea5): a high-resolution seasonal forecast system, Q. J. Roy. Meteor. Soc., 141, 1072-1084, https://doi.org/10.1002/qj.2396, 2015.

Mackay, J. D., Jackson, C. R., Brookshaw, A., Scaife, A. A., Cook, J., and Ward, R. S.: Seasonal forecasting of groundwater levels in principal aquifers of the United Kingdom, J. Hydrol., 530, 815828, https://doi.org/10.1016/j.jhydrol.2015.10.018, 2015.

Molteni, F., Stockdale, T., Balmaseda, M., Balsamo, G., Buizza, R., Ferranti, L., Magnusson, L., Mogensen, K., Palmer, T., and Vitart, F.: The new ECMWF seasonal forecast system (system 4), ECMWF Technical Memorandum 656, ECMWF, Shinfield Park, Reading, available at: http://www.ecmwf.int/en/elibrary/ 11209-new-ecmwf-seasonal-forecast-system-system-4 (last access: 25 February 2018), 2011.

Nedellec, R., Cugliari, J., and Goude, Y.: GEFCom2012: Electric load forecasting and backcasting with semi-parametric models, Int. J. Forecast., 30, 375-381, 2014.

Palin, E. J., Scaife, A. A., Wallace, E., Pope, E. C. D., Arribas, A., and Brookshaw, A.: Skilful seasonal forecasts of winter disrup on to the UK transport system, J. Appl. Meteorol. Clim., 55, 325344, https://doi.org/10.1175/jamc-d-15-0102.1, 2016.

Pfenninger, S. and Staffell, I.: The increasing impact of weather on electricity supply and demand, Energy, 145, 65-78, 2018.

Pierrot, A. and Goude, Y.: Short-Term Electricity Load Forecasting with Generalized Additive Models, Proceedings of ISAP power, 593-600, 2011.

REN21: Renewables 2016 Global Status Report (Paris: REN21 Secretariat), available at: http://www.ren21.net/gsr-2016/ (last access: 15 August 2018), 2016.

Rienecker, M. M., Suarez, M. J., Gelaro, R., Todling, R., Bacmeister, J., Liu, E., Bosilovich, M. G., Schubert, S. D., Takacs, L., Kim, G.-K., Bloom, S., Chen, J., Collins, D., Conaty, A., da Silva, A., et al.: MERRA - NASA's Modern-Era Retrospective Analysis for Research and Applications , J. Climate, 24, 36243648, https://doi.org/10.1175/JCLI-D-11-00015.1, 2011.

Saint-Drenan, Y.-M., Bofinger, S., Fritz, R., Vogt, S., Good, G.-H., and Dobschinski, J.: An empirical approach to parameterizing photovoltaic plants for power forecasting and simulation, Sol. Energy, 120, 479-493, https://doi.org/10.1016/j.solener.2015.07.024, 2015.

Saint-Drenan, Y.-M., Good, G. H., and Braun, M.: A probabilistic approach to the estimation of regional photovoltaic power production, Sol. Energy, 147, 257-276, 2017.

Saint-Drenan, Y.-M., Wald, L., Ranchin, T., Dubus, L., and Troccoli, A.: An approach for the estimation of the aggregated photovoltaic power generated in several European countries from meteorological data, Adv. Sci. Res., 15, 51-62, https://doi.org/10.5194/asr-15-51-2018, 2018.

Silva, V. and Burtin, A.: Technical and Economic Analysis of the European System with $60 \%$ RES, EDF Technical Report, available at: https://www.edf.fr/sites/default/files/Lot3/ CHERCHEURS/Portraitdechercheurs/summarystudyres.pdf (last access: 3 July 2018), 2015.

Staffel, I. and Pfenninger, S.: Using bias-corrected reanalysis to simulate current and future wind power output, Energy, 114, 1224-123, 2016.

Svensson, C., Brookshaw, A., Scaife, A. A., Bell, V. A., Mackay, J. D., Jackson, C. R., Hannaford, J., Davies, H. N., Arribas, A., and Stanley, S.: Long-range forecasts of UK winter hydrology, Environ. Res. Lett., 10, 064006, https://doi.org/10.1088/17489326/10/6/064006, 2015.

Thornton, H. E, Hoskins, B. J., and Scaife, A. A.: The role of temperature in the variability and extremes of electricity and gas demand in Great Britain, Environ. Res. Lett., 11, 114015, https://doi.org/10.1088/1748-9326/11/11/114015, 2016.

Troccoli, A.: Seasonal climate forecasting, Meteorol. Appl., 17, 251-268, https://doi.org/10.1002/met.184, 2010.

van Vliet, M. T. H., Wiberg, D., Leduc, S., and Riahi, K.: Powergeneration system vulnerability and adaptation to changes in climate and water resources, Nat. Clim. Change, 6, 375-380, 2016.

Viel, C., Beaulant, A.-L., Soubeyroux, J.-M., and Céron, J.-P.: How seasonal forecast could help a decision maker: an example of climate service for water resource management, Adv. Sci. Res., 13, 51-55, https://doi.org/10.5194/asr-13-51-2016, 2016.

Voldoire, A., Sanchez-Gomez, E., Salas y Mélia, D., Decharme, B., Cassou, C., Sénési, S., Valcke, S., Beau, I., Alias, A., Chevallier, M., Déqué, M., Deshayes, J., Douville, H., Fernandez, E., Madec, G., Maisonnave, E., Moine, M.-P., Planton, S., SaintMartin, D., Szopa, S., Tyteca, S., Alkama, R., Belamari, S., Braun, A., Coquart, L., and Chauvin, F.: The CNRM-CM5.1 global climate model: Description and basic evaluation, Clim. Dynam., 40, 2091-2121, 2013.

Weedon, G. P., Balsamo, G., Bellouin, N., Gomes, S., Best, M. J., and Viterbo, P.: The WFDEI meteorological forcing data set: WATCH Forcing Data methodology applied to ERAInterim reanalysis data, Water Resour. Res., 50, 7505-7514, https://doi.org/10.1002/2014WR015638, 2014.

Weisheimer, A. and Palmer, T. N.: On the reliability of seasonal climate forecasts, J. R. Soc. Interface, 11, 20131162, https://doi.org/10.1098/rsif.2013.1162, 2014.

Wilks, D. S.: Chapter 8 - Forecast Verification, International Geophysics, 100, 301-394, https://doi.org/10.1016/b978-0-12385022-5.00008-7, 2011.

Wood, S. N.: Generalized Additive Models: An Introduction with R, CRC/Chapman \& Hall, Boca Raton, 2006. 